DEPÓSITO LEGAL ZU2020000153

Esta publicación científica en formato digital

es continuidad de la revista impresa

ISSN 0041-8811

E-ISSN 2665-0428

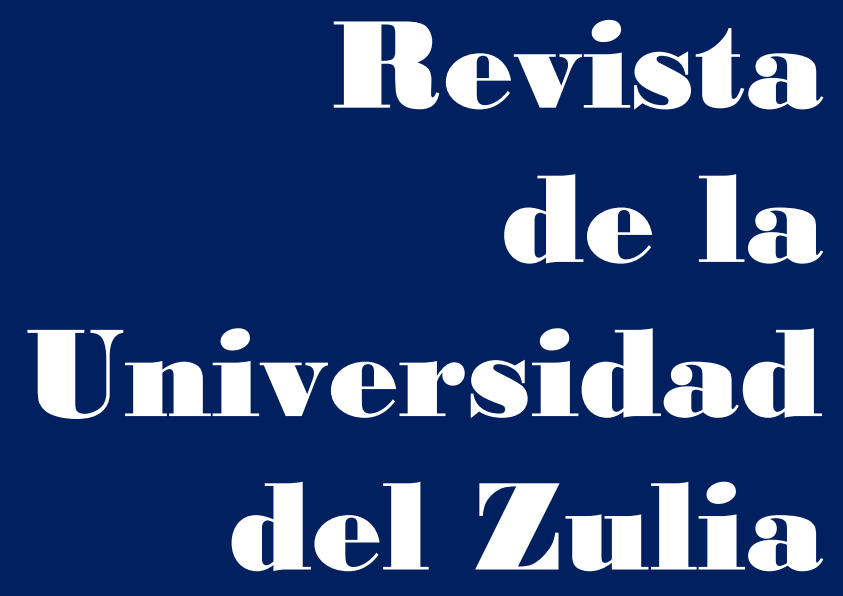

Fundada en 1947

por el Dr. Jesús Emrique Lossada

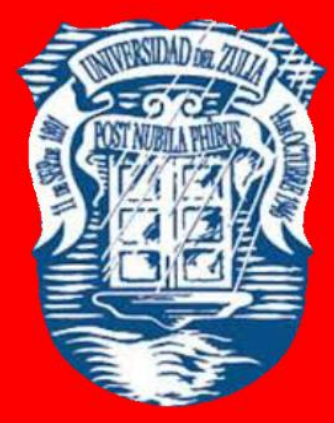

Ciencias

Sociales

y Arte

Año $12 \quad N^{\circ} 34$

Septiembre - Diciembre 2021

Tercera Época

Maracaibo-Veneruela 


\title{
La pesca artesanal en Ecuador: miradas desde el desarrollo sostenible y la globalización
}

\author{
Jorge Armando Zambrano-Campoverde * \\ Laura Alexandra Guachichullca-Ordóñez ** \\ Manuel Horacio Valdiviezo-Cacay ***
}

RESUMEN

En este artículo se presenta una visión integral del fenómeno socioproductivo que significa la pesca artesanal en el Ecuador, con un seguimiento desde su concepción teórico-conceptual, hasta la manera en que se ha ido articulando a las demandas del enfoque de la sostenibilidad ambiental, así como su caracterización frente a la globalización. El enfoque metodológico utilizado para desarrollar esta investigación se corresponde con la visión cualitativa hermenéutica, sustentada en artículos de actualidad publicados en bases de datos especializadas. En la actualidad, hay pocas dudas acerca de la necesidad de transformación continua que requiere el sector pesquero artesanal, esos cambios son parte de la urgencia que existe para no ser arropado por la dinámica de una economía globalizadora que, en su afán de allanar los obstáculos para el desarrollo (entendido en sus variables economicistas) puede atropellar los principios de la calidad ambiental que implica el "buen vivir".

PALABRAS CLAVE: pesca costera; pesca artesanal; desarrollo sostenible; globalización, industria artesanal.

*Profesor de la Universidad Técnica de Machala, Ecuador. Miembro del Equipo de Investigación sobre Características socioeconómicas de la población pesquera artesanal del perfil costero de la provincia de El Oro, periodo 2019-2020. ORCID: https://orcid.org/0000-0003-0062-4895. E-mail: jzambrano@utmachala.edu.ec

**Profesora de la Universidad Técnica de Machala, Ecuador. Miembro del Equipo de Investigación sobre Características socioeconómicas de la población pesquera artesanal del perfil costero de la provincia de El Oro, periodo 2019-2020. ORCID: https://orcid.org/0000-0003-1113-7769. E-mail: lguachichullca@utmachala.edu.ec

***Profesor de la Universidad Técnica de Machala, Ecuador. Miembro del Equipo de Investigación sobre Características socioeconómicas de la población pesquera artesanal del perfil costero de la provincia de El Oro, periodo 2019-2020. ORCID: https://orcid.org/0000-0001-7082-2921. E-mail: mvaldiviezo@utmachala.edu.ec

Recibido: 02/07/2021

Aceptado: 10/08/2021 


\section{Artisanal fishing in Ecuador: glances from a sustainable development and globalization}

ABSTRACT

This article presents an integral vision of the socioproductive phenomenon symbolized by artisanal fishing in Ecuador, with a monitoring from its theoretical-conceptual understanding, to the way in which it has been articulated into the demands for environmental sustainability, as its characterization regarding globalization. The methodological approach used to develop this research corresponds to the qualitative hermeneutic vision, supported by recent articles published in specialized databases. Currently, there are few doubts regarding the need for constant transformation that is required by the artisanal fishing sector, as such changes are part of the existing urgency to avoid being buried by the dynamics of a globalized economy which, in its eagerness to overcome obstacles for development (understanding its economistic variables) may trample on the environmental quality principles that "good living" implies.

KEYWORDS: seaside fishing; artisanal fishing; sustainable development; globalization; artisanal industry.

\section{Introducción}

Una de las preocupaciones con mayor recurrencia en el contexto latinoamericano y en el resto del mundo, tiene que ver con la seguridad alimentaria, sus perspectivas y sus garantías, a la luz de un proceso globalizador, cada vez más agresivo y depredador de la naturaleza. No se puede olvidar que esta última es, finalmente, esa fuente desde donde se producen o extraen los alimentos de la humanidad. Desde nuestra convicción intelectual, se impone entonces una profunda reflexión acerca de lo que se está haciendo en Latinoamérica, especialmente en países como Ecuador, para enfrentar esa preocupación y proponer una visión de futuro, en la que las nuevas generaciones, cuenten con un planeta en el cual se pueda desarrollar una vida plena.

Ese buen vivir, del que tanto se ha hablado y sobre el que se ha legislado con suficiencia en Ecuador, está asociado a la posibilidad de mantener la sostenibilidad y sustentabilidad de los recursos alimentarios con que cuenta la nación, entre ellos, aquellos que derivan de la actividad pesquera. Es esta actividad alimentaria una de las más antiguas, pero -también- una de las más 
problemáticas para la aplicación de políticas públicas coherentes con las necesidades de la población ecuatoriana. A pesar de los esfuerzos jurídicos que se han hecho en este ámbito, no siempre es posible articular las acciones locales, regionales y nacionales para enfrentar las contradicciones del desarrollo globalizador que debe resolver el sector pesquero en el país.

Dicho esto, la intención de este artículo se inscribe en ese marco general de pensamiento, pero con un particular detenimiento en las características que muestra el área de la pesca artesanal en Ecuador, de cara al fortalecimiento de una visión humanista y sostenible del desarrollo, más allá de la radicalidad que han representado -desde sus planteamientos inicialeslas explotaciones industriales en las zonas de pesca artesanal del país. En este caso, el enfoque de la sostenibilidad, es subsidiario de la visión crítica, no como una mera postura de rebeldía intelectual, sino como parte de la necesidad de reconocer los efectos indeseados que, tanto en lo económico como en lo sociocultural, representa el modelo globalizador.

En ese orden de ideas, es comprensible que la subsistencia de los sectores primarios de la economía, particularmente los que están relacionados con la pesca, requieran una alianza con las estrategias actuales que impone el mercado. Pensar en la autarquía del sector, no solo sería ingenuo, sino un suicidio socioeconómico, pues la impronta de la globalización se encuentra por todos lados. Y es que, como afirma Coppelli (2018: 60), "desde hace ya algún tiempo, el término globalización está presente en todos los ámbitos, tanto académicos como extra-académicos. Cualquier situación que guarde relación con conexión, cercanía, traslado o movimiento, nos aproxima a su definición".

Considerando este tipo de observaciones, la propuesta en este ejercicio de investigación es realizar una aproximación, desde la hermenéutica crítica a la discusión teórico-práctica, que se ha desarrollado alrededor del tema de la pesca artesanal en Ecuador, no como un registro documental anecdotario, sino como un esfuerzo de comprensión de la relación antagónica, pero necesaria entre estos sectores ligados a la cultura alimentaria de los pueblos, sus luchas por mantenerse en los límites que la misma naturaleza les impone (en convivencia armónica), y las exigencias de una economía que demanda productividad a gran escala y permanente conexión con los estándares internacionales del desarrollo. 
1. Fundamentaciones teórico-prácticas de la pesca artesanal

Cuando se habla de pesca artesanal, independientemente del contexto geo-temporal, se hace alusión a esa actividad pesquera, con una perspectiva fundamentalmente de subsistencia, que ejecutan algunas personas sin mayor mecanización. La inversión que se realiza para llevar adelante la pesca de carácter artesanal tiende a ser pequeña, pues se utilizan equipos relativamente rudimentarios, muchas veces construidos por los mismos pescadores, con materiales que ellos mismos se proveen. De acuerdo con Méndez (2020), quienes se dedican a la pesca artesanal tienen un radio de acción limitado por su capacidad de movilización, que no es mucha, pero -sobre todo- por sus costumbres, saberes, las características de las fuentes de agua y solo -en última instancia- por las demandas del mercado.

Una de las características más frecuentes de la pesca en esta escala, es la presencia del núcleo familiar en las labores de obtención y distribución del recurso pesquero, así como de la canalización de las actividades que la hacen posible. Es también una constante, en la ejecución de la pesca artesanal, encontrar actualmente modificaciones que son producto de la afectación que sobre el ambiente y las fuentes hídricas ha tenido la pesca industrializada. Esta situación es -justamente- una de las circunstancias que obliga a los trabajadores artesanales del sector a mantenerse alerta acerca de las prácticas depredadoras que realizan, quienes acostumbran esta actividad económica a gran escala, para prepararse ante esos efectos.

En cuanto al aspecto ambiental, ciertamente la pesquería artesanal se distingue por su respeto a la naturaleza y el cuidado sobre los equilibrios ecológicos. A decir de Solís y Díaz (2018), esta característica da cuenta de filiación que se genera entre los pescadores y los ecosistemas marinos, en las diferentes regiones donde se desarrolla la actividad. El mismo autor destaca que, la propia definición de esta actividad, es compleja, si no se advierte esa necesaria compatibilidad entre la extracción del recurso pesquero y la conservación de sus potencialidades, jugando un papel importante aquí las herramientas y técnicas utilizadas por los trabajadores que deben ser poco invasivas y respetuosas de la sostenibilidad de las fuentes hídricas.

La pesquería artesanal conjuga así una serie de dimensiones que la presentan como una actividad social, económica y cultural al mismo tiempo. Mirada desde la perspectiva social, es 
una opción para muchas familias que habitan extensos territorios cercanos a las fuentes marinas y que ven en ella la posibilidad de obtener los recursos, tanto alimentarios como de ingresos monetarios para enfrentar la pobreza. De allí se desprenden sus rasgos económicos, siendo que, en los últimos años, ha sido uno de los sectores de mayor crecimiento, representando dentro del mundo de la pesca en general, un altísimo porcentaje y, contribuyendo, decisivamente, a la economía global (López \& Espeso, 2020).

Desde el punto de vista cultural, “...la pesca en América Latina tiene antecedentes que se remontan a épocas prehispánicas, por lo que constituye una práctica económica con fuertes dimensiones culturales y sociales para los pueblos originarios que la desarrollaron" (Salazar, 2013, pág. 5). Por esto, hay que estar conscientes que, a pesar de la perdurabilidad en el tiempo de la actividad pesquera, en su versión artesanal, han sido muchos los cambios que ha sufrido y -con ellos- influido sobre las prácticas culturales de las que derivó. Ese impacto cultural se siente como parte de las dinámicas productivas que están enlazadas en las transformaciones que provoca el mercado de alimentos global.

En suma, la pesca artesanal, aunque mantiene ciertos rasgos distintivos propios de su origen antiguo, enfrenta a diario fuertes tensiones con los centros de producción de las políticas públicas que, en Latinoamérica -como en otras partes del mundo- tienden a favorecer la industrialización y la globalización de los procesos económicos. De hecho, el crecimiento de la pesca a esa escala industrial que se generó posterior a la Segunda Guerra Mundial, significó nuevos obstáculos para aquellos trabajadores de la pesquería, ubicados en el sector de mayor vulnerabilidad económica y social. El crecimiento de la demanda mundial impulsó la introducción de técnicas más especializadas que permitieran una mayor productividad, afectando directamente la pesca de subsistencia, artesanal o de pequeña escala, como también se le conoce.

2. La actividad pesquera artesanal en Ecuador: generalidades

La pesca artesanal en el territorio ecuatoriano es una de las actividades económicas y socioculturales de mayor arraigo en ciertas zonas del país. Sin embargo, según algunos autores, como León et al. (2017), en Ecuador, la pesca en general no es una de las actividades económicas 
más florecientes. En realidad, podría considerarse un sector emergente que aún mantiene predominio de técnicas de carácter artesanal y -por ende- su industrialización se encuentra limitada. Estos rasgos derivan de la congruencia entre las convicciones que mantienen los pescadores, desde el punto de vista cultural, y sus incapacidades para hacer inversiones a gran escala, dadas las condiciones socioeconómicas en las que la mayoría de ellos vive, así como las limitaciones o regulaciones impuestas por el Estado.

Conceptualmente, la pesquería artesanal o a pequeña escala en el país, representa una opción de vida para las comunidades ecuatorianas, la mayoría de origen socioeconómico con mayor posibilidad de vulnerabilidad en su derecho a la alimentación, que optan por dedicarse a ese oficio como alternativa de subsistencia, en algunos casos, o como mecanismo de movilidad social. En su gran mayoría, estos pescadores utilizan pequeñas o medianas embarcaciones movilizadas manualmente o con motores de pocas dimensiones para sus actividades, además, usan materiales manuales para la captura del recurso pesquero.

No solo en el territorio ecuatoriano, sino en otras latitudes, la producción de la pesca artesanal suple una buena cantidad de los nutrientes que requieren las poblaciones de menores recursos, representando una verdadera alternativa, frente al costo de los alimentos de primera necesidad en la mayoría de los países de Latinoamérica. Incluso, la aparición de las flotas industriales para la pesca a gran escala, lo único que han logrado es el encarecimiento de un producto animal que, para los pueblos y las nacionalidades indígenas, siempre ha estado allí, como una contribución de la naturaleza, sin mayores condicionamientos que la preservación de los equilibrios ecológicos.

Las características naturales de este país refuerzan esa percepción de la posibilidad de la pesca como un verdadero premio de la madre tierra, pues, Ecuador cuenta con una gran extensión de aguas territoriales, que quintuplica su disponibilidad de superficie terrestre, presentando además, un auténtico santuario ecológico, como lo es las “Islas Galápagos" (Soriano, 2019). No extraña entonces, que un numeroso grupo de poblaciones ecuatorianas mantengan una trayectoria fuertemente ligada a la explotación pesquera, particularmente de corte artesanal, la cual -por cierto- es la encargada de suplir el consumo de pescado en el país, al tiempo que abastece algunas demandas específicas del sector exportador de productos pesqueros. 
A pesar de tener esa importancia para la seguridad alimentaria del país, la pesca artesanal ha sido poco atendida desde las políticas públicas, al menos, en comparación con lo que ha sido el impulso dado a la acuacultura; es decir, la producción y comercialización de camarones. De hecho, esa atención privilegiada de la acuacultura, tiene un doble efecto sobre la actividad pesquera artesanal: por un lado les coloca en minusvalía institucional, al ser discriminados por el Estado y la inversión pública; y, por el otro, la forma intensiva en que se asentaron las industrias camaroneras, afectaron los ecosistemas y la existencia de las especies marinas, reduciendo la capacidad de trabajo productivo para los pescadores artesanales.

\section{2.l. De las condiciones originarias y la evolución de la pesca artesanal en Ecuador}

Las características naturales del Ecuador, lo hacen un país con una gran diversidad en cuanto a clima, suelo, vegetación y fauna, que le provee de muchas potencialidades cuando de desarrollar actividades productivas se trata (Hernández y Hurtado, 2020). La ganadería y la agricultura son parte fundamental de su estructura económica y a ello hay que sumarle la disponibilidad de más de $600 \mathrm{~km}$ de costa del Pacífico que es una fuente inagotable para la pesca, tanto industrial como artesanal, así como el turismo, que también adquiere dimensiones importantes por estas circunstancias que le da la naturaleza (Zurita, 2016).

En lo que respecta a la pesca artesanal, sus orígenes pueden rastrearse hasta las actividades de recolección manual de mariscos, realizada por los pueblos originarios hasta la inclusión de tecnologías primarias que permiten la incursión en algunas zonas de mar abierto (León et al., 2017). Su evolución se enlaza con el redimensionamiento que ha sufrido a nivel mundial el sector pesquero, el cual, “...es el sector alimentario con mayor dinamismo a nivel global, con una tasa de crecimiento anual promedio de $8.8 \%$, desde mediados de la década de los 80" (Celaya \& Almaraz, 2018).

Ese comportamiento económico implica a la pesquería artesanal y ha propiciado todo un movimiento de adecuación de sus actividades, tanto desde el punto de vista práctico, en la adopción de nuevas técnicas y estrategias pesqueras, hasta la asimilación de las exigencias de las políticas públicas que establecen regulaciones para impulsar la actividad, pero -también- para regular su desempeño. Es así como la importancia que adquiere el sector pesquero en Ecuador se 
puede visualizar cuando, conjuntamente con la agricultura, se constituye en una de las actividades productivas de mayor crecimiento sostenido desde finales de la segunda década de este siglo.

Gracias a las bondades del clima tropical y templado que posee Ecuador, los pescadores se privilegien de tener una diversidad de riqueza marina donde destacan muchos peces que representan a Ecuador en varios mercados, como lo son: el Atún, Dorado o el Camarón. La diversidad de productos pesqueros y la pesca, al ser una actividad de origen ancestral permiten que la experiencia adquirida durante décadas ejemplifique a Ecuador como un país con actividad pesquera de alto potencial, lo que lo catapulta a ser un referente en los mercados mundiales de la Pesca.

Estas condiciones favorables, se fortalecen en la medida en que el consumo y comercialización del pescado se acrecienta, no solo entre la población ecuatoriana, sino a nivel mundial. La importancia de esto se redimensiona en un contexto en el que la alimentación sigue siendo uno de los derechos a preservar a nivel mundial; la pesca artesanal se erige como una de las principales alternativas para enfrentar las dificultades que persisten en ese ámbito. De hecho, en el caso ecuatoriano, las décadas que van desde 1990 hasta el 2020 han sido de crecimiento de la producción que -en líneas generales- ha alcanzado a proveer, aproximadamente unas 600 toneladas al mercado (Zurita, 2016).

Tomando en cuenta estas observaciones estadísticas, se puede decir que la pesquería artesanal se ha visto obligada a "caminar" a un ritmo más acelerado debido a las exigencias que le impone el proceso de globalización de la economía que, aunque no incorpore de facto a los pescadores o industrias de pequeña escala, se conectan a ellos en el entramado sociocomercial que implica la exportación de muchas especies de peces, cuya transacción se realiza en los puertos pesqueros artesanales del país. Siendo así, es imposible que los pobladores dedicados al oficio artesanal de la captura de peces, se desliguen completamente de las determinaciones que impone el mercado internacional y, en tanto, su evolución en el contexto local se encuentra ligado a las transformaciones que impone la globalización.

2.2. Del perfilamiento socioeconómico de la pesca artesanal en Ecuador 
El perfil sociocultural que adquiere este sector que hemos venido analizando es producto, más que de una evolución armónica, de las contradicciones que provoca su fortalecimiento frente a las fuerzas dominantes del mercado internacional. Dentro del mismo territorio ecuatoriano, se libran debates y se enfrentan visiones en torno a las facilidades u obstáculos para el sector pesquero a pequeña escala. Las políticas públicas y las iniciativas de carácter jurídico, sin embargo, han representado un punto de apoyo importante para que los trabajadores en esta actividad económica se mantengan y puedan obtener de ella, más que la subsistencia, un nivel adecuado a los parámetros del modelo societal que promete la teoría del "buen vivir".

Según Pazmiño (2017), quienes están dedicados a la pesca artesanal en Ecuador, mantienen un perfil socioeconómico verdaderamente complejo, debido a que su vulnerabilidad y pobreza, derivan de falencias estructurales que, a pesar de algunos esfuerzos realizados desde las políticas públicas en los últimos años, no se han podido revertir. Estos trabajadores mantienen una exclusividad con su actividad, de manera que -cualquier dificultad en ella- se refleja en sus condiciones socioeconómicas. Las familias están en su mayoría relacionadas en pleno con las acciones que demanda el trabajo y, en muchas ocasiones, los niños ni siquiera acuden a los centros educativos, sino que -desde muy temprana edad-se incorporan a la actividad pesquera.

Entre los rasgos distintivos que, el mismo Pazmiño (2017) destaca en su caracterización de la actualidad de la pesca artesanal, se pueden mencionar: a) la precariedad de infraestructura en que se encuentran las caletas artesanales donde los pescadores deben desembarcar sus productos; b) la incorporación, cada vez más numerosa de pescadores artesanales, ante la contracción de otras áreas de trabajo, lo que presiona sobre la disponibilidad del recurso pesquero y, por ende, el ingreso de las familias; c) la inestabilidad de los precios a que se paga el producto, especialmente a nivel de playa, que afecta también el ingreso por concepto de la actividad para las familias dedicadas a la pesquería artesanal y; d) las dificultades que se le presentan a las flotas artesanales para mantener y actualizar sus medios de captura y procesamiento de sus productos.

Todas estas características socioeconómicas de la pesquería artesanal, repercuten de forma negativa en su fortalecimiento como alternativa laboral para las familias que habitan la 
región costera del país y las coloca en una posición difícil, desde el punto de vista del acceso a los bienes y servicios, pues, la mayoría solo cuenta con esta actividad para obtener sus medios de subsistencia. Sin embargo, también es necesario señalar que hay acciones que el Estado y los mismos pescadores artesanales organizados han realizado y continúan realizando para mantener vigente y rentable la pesquería artesanal.

\subsubsection{En cuanto a comercialización del producto}

Está claro que la pesca artesanal, tanto en Ecuador como en otras partes del mundo, no está pensada desde la perspectiva de una extensiva comercialización de sus productos, por tanto, lo que se busca es mantener un nivel de rentabilidad acorde con las necesidades de una familia promedio que requiere vivir dignamente. En esta dimensión de la actividad se pueden detectar una serie de elementos problemáticos que tienen que ver con la relación costo beneficio, generalmente desfavorable para los pescadores; la capacidad de gestión del pescador artesanal, que suele ser precaria; y el descuido institucional para fomentar $y / o$ proteger los procesos de comercialización del pescado a pequeña escala. En general, en la figura 1, se presenta un resumen de los problemas económicos o comerciales que enfrenta la pesquería artesanal.

\subsubsection{En cuanto a la tipología de la pesca artesanal y sus puertos}

Así como se puede hablar de una clasificación de la pesca, entre industrial y artesanal, a lo interno de esta última, también es posible realizar una distinción: para Pazmiño et al (2017), es posible encontrar un tipo de pesca artesanal que se desarrolla en las Islas Galápagos y la pesca artesanal marítima del continente. A su vez, en la marítima continental se pueden distinguir tres tipos: de recolección, costera y oceánica. En todo caso, la tradición que tiene el país y la experiencia en el manejo de los recursos derivados de la pesquería, le permiten mantener una actividad que, en su esencia es respetuosa del equilibrio ambiental y los principios de sostenibilidad y sustentabilidad. 




Figura l. Perfil de mercado y comercialización de la pesca artesanal Fuente: elaboración propia, basada en Pazmiño (2017).

En la expansión y fortalecimiento de la actividad de pesca artesanal es importante que se considere la existencia y mantenimiento de los puertos y caletas pesqueras que posee el país. "Actualmente los puertos pesqueros de mayor importancia a nivel artesanal, y que representan aproximadamente el 70 \% del desembarque del país son: Esmeraldas, Manta, Puerto López, Anconcito, Santa Rosa y Puerto Bolívar" (Herrera et al., 2014: 3). Cada uno de estos puertos, no solo representan el centro neurálgico para la actividad de la pesca; en realidad, conforman el dispositivo socializador de la región, desde el que se dinamizan los procesos sociales, económicos y culturales de las poblaciones aledañas. En la figura 2, se sinteiza una caracterización de tres de los principales puertos para pesca artesanal: 

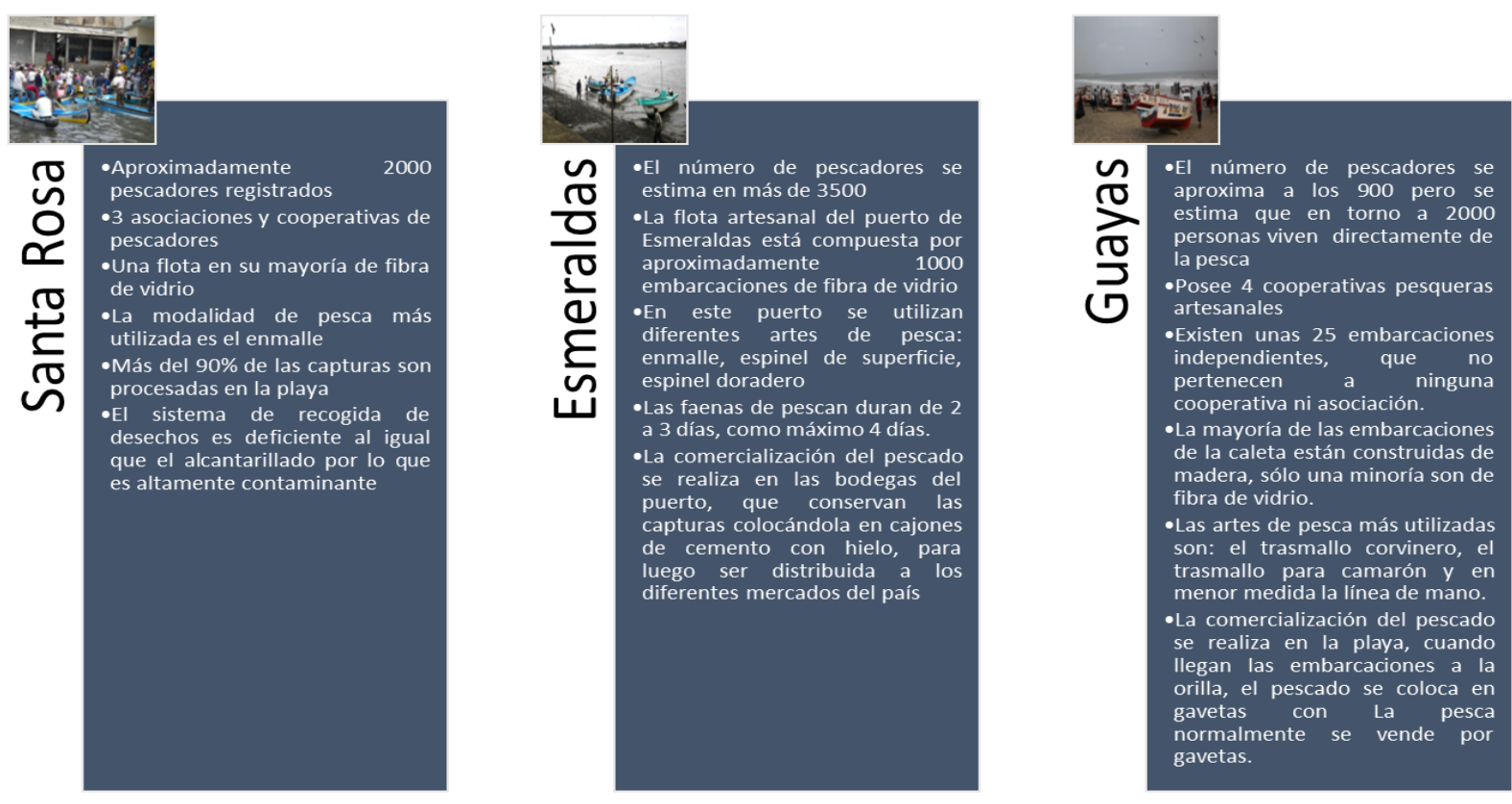

Figura 2. Perfil de mercado y comercialización de la pesca artesanal Fuente: elaboración propia

En general, la investigación realizada en torno a los aspectos conceptuales y los datos empíricos sobre el estado de la pesca artesanal en el Ecuador, considerando su perfil socioeconómico, nos reafirma la imagen de un sector compuesto por una gran diversidad de grupos humanos, nada homogéneos, incluso entre ellos mismos, pero con una larga tradición de trabajo y mística para desarrollar su labor. Igualmente, aunque no fue materia de esta indagatoria ha habido importantes avances en cuanto a las políticas públicas asociadas al robustecimiento y protección del sector, a pesar de los embates de una economía globalizadora que cada día exige más uniformidad y productividad, por lo que se contrapone a los principios originarios de la actividad artesanal, cualquiera sea el ámbito económico del que se trate.

En este orden de ideas, uno de los elementos constantemente vinculados a la actividad de la pesquería artesanal, tiene que ver con la afectación del ambiente o -más bien- su protección. Las prácticas de los pescadores a pequeña escala, tienden a ser respetuosas del equilibrio ambiental y suele tener el enfoque ecosistémico como orientador de sus actividades. En el cierre del texto del artículo, nos aproximaremos a esa relación siempre problemática entre 
productividad y desarrollo sostenible, teniendo como referencia la pesca artesanal y las imposiciones factuales del proceso globalizador de la economía.

\section{El desarrollo sostenible y la pesca artesanal en Ecuador}

Los sistemas pesqueros en el mundo y, especialmente en Ecuador, forman parte de esas actividades económicas que, por sus características, se encuentran estrechamente vinculadas a la filosofía del desarrollo sostenible. Esta afinidad es comprensible, puesto que las manifestaciones que tiene en la actualidad el deterioro ambiental, promueven una nueva cosmovisión del mundo, para la cual, es central el tema de la humanización del desarrollo, basado en una nueva ética y una vinculación axiológica y no depredadora, entre el ser humano y la naturaleza, incluyendo -por supuesto- la explotación de los recursos pesqueros (Vázquez \& Terazone, 2017).

Es así como, desde el punto de vista institucional, en el país hay un conjunto de organismos encargados de velar por el comportamiento del sector pesquero, de manera que sus actividades mantengan los estándares de resguardo ambiental, coherentes con el enfoque ecosistémico y, por ende, con la concepción de la sostenibilidad y sustentabilidad. Se entiende que los niveles expansivos de la demanda del producto pesquero, aunado al incremento del consumo en el mercado nacional, presionan insistentemente, por la utilización de técnicas de industrialización de la pesca que pueden terminar afectando gravemente las fuentes de este recurso y, en consideración a esa posibilidad, es que se constituye ese entramada institucional que planifica, administra y ejecuta la aplicación de las políticas públicas en esta área. Ese sistema institucional se muestra en el grafico 3.

En general, cada una de estas instituciones tiene sus objetivos, unos más específicos que otros, dependiendo el nivel del que se trate. En el caso que nos ocupa-que es el de pesca artesanal y sus relaciones con el enfoque de la sostenibilidad- la dependencia que la regula, como se ve en el organigrama, se encuentra en el plano más cercano a la realidad. Podría pensarse que por su propia esencia, la pesca de pequeña escala es respetuosa de los equilibrios ambientales. Sin embargo, es preciso que la presencia del Estado vele por este equilibrio, porque dada cuenta de las presiones de una globalización económica que está empujando cada vez más a la 
intensificación de la producción, puede repercutir en prácticas de pesca con un mayor grado de depredación ecológica.

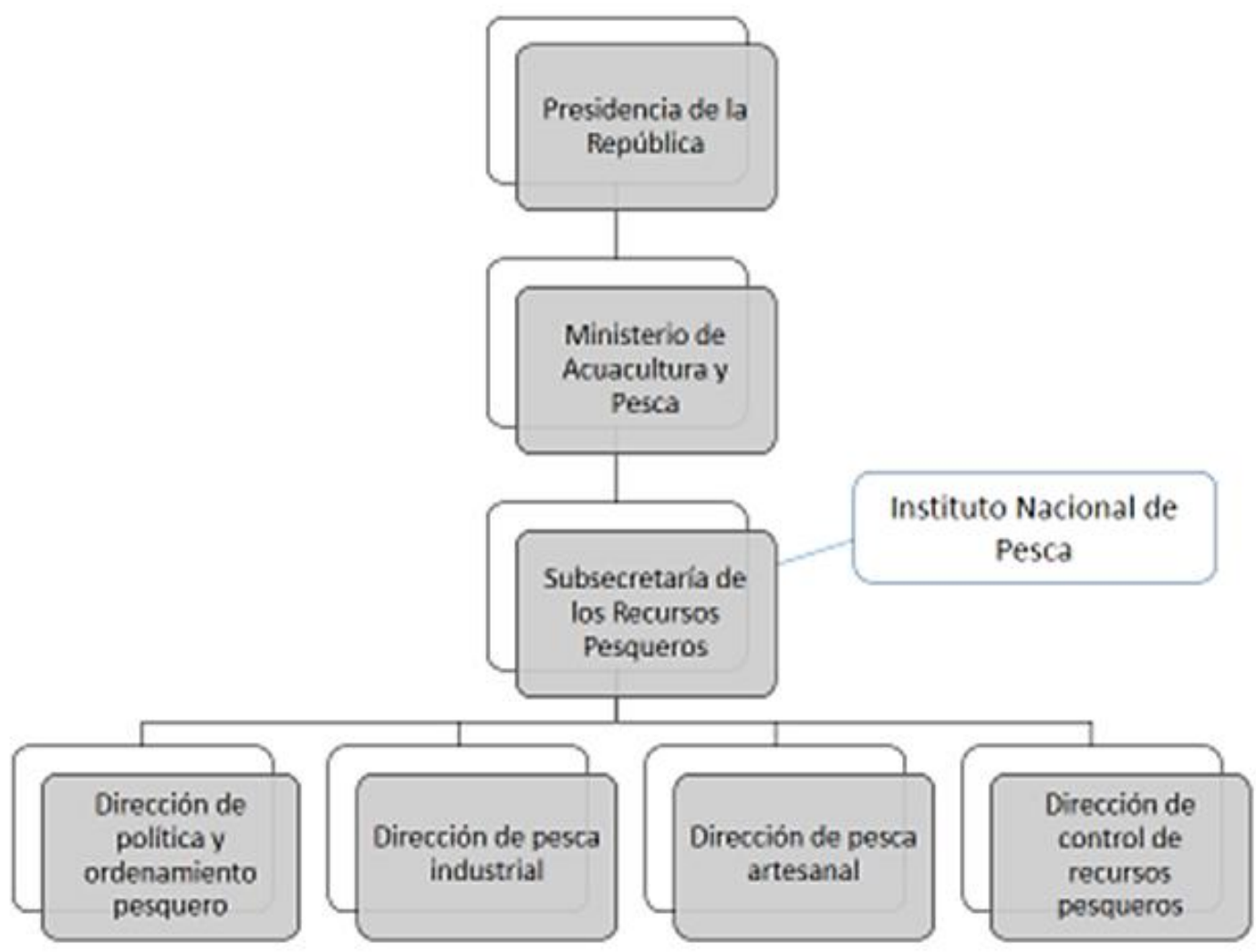

Figura 3. Los componentes institucionales del sector pesquero en el Ecuador Fuente: Ministerio de Acuacultura y pesca (2020)

Igualmente, en el análisis de las condiciones portuarias en las que se comercializa la pesca artesanal, fue posible encontrar serias debilidades en cuanto a los mecanismos de deposición de los desechos pesqueros y los sistemas de alcantarillado de estos puertos. Estas circunstancias, activan las alarmas para que los pescadores artesanales, a partir de sus propias organizaciones cooperativas, puedan impulsar -bien sea desde sus propios recursos o a través de la presión sobre las instituciones- para que estas condiciones puedan combatirse y crear espacios portuarios con un mayor nivel de sanidad ambiental, coherentes con las perspectivas que impone el enfoque del desarrollo sostenible. 
4. Epílogo de una relación: Sostenibilidad, pesca artesanal y perspectivas del desarrollo sostenible en Ecuador vistos desde la globalización

Aunque el subtítulo de este apartado parezca afirmar la existencia de "una sola globalización", a estas alturas del debate sobre el tema, ha quedado entendido que este proceso es diverso y sus facetas van desde lo axiológico, pasando por lo cultural, lo político y -por supuesto- lo económico. Esa comprensión integral del fenómeno globalizador, es lo que se puede observar en las diferentes iniciativas estatales y culturales que se han activado en Ecuador, cuando se analiza la pesca artesanal en sus relaciones con el desarrollo sostenible. El Estado ecuatoriano ha diversificado la institucionalidad alrededor de la actividad pesquera, de forma que -en su versión artesanal- pueda estar protegida, pero no solo para permanecer como un sector subsidiario de la vida de los pescadores de este nivel, sino que se fortalezca como espacio cultural y potenciador del buen vivir.

Ese comportamiento estatal es congruente con la importancia que ha adquirido el producto pesquero a nivel mundial, en una sociedad globalizada que ha visto acrecentar la demanda y el consumo del pescado. En muchos países de Europa y Asia, por ejemplo, se puede observar la relevancia que se le da a la capacidad nutricional y alimentaria de este producto, debido a los problemas de obesidad o déficit nutricional que se presenta en algunas de estas latitudes (Pedroza, 2020). Dada esta situación impuesta por el proceso globalizador, algunos puertos pesqueros artesanales, se han visto en la obligación de incorporar modificaciones en cuanto al tratamiento, conservación y distribución del producto que permita la sostenibilidad de la actividad y -en esa medida- la rentabilidad para los trabajadores del sector.

Desde este punto de vista, en el caso ecuatoriano se puede afirmar que ha ocurrido un proceso pausado, pero continuo que mantiene la perspectiva positiva de la inclusión de la pesca artesanal en esa dinámica propia del mercado global, aunque sin perder su esencia, marcada por la cultura del pescador nacional y sus técnicas tradicionales. Sin embargo, obviar las exigencias que impone esa dinámica sería un error grave para la existencia de la actividad, porque ni los pescadores ni el Estado, pueden ignorar que la globalización implica mayores niveles de eficiencia y eficacia en la producción, que no siempre las actividades de captura artesanal pueden cubrir. De lo que se trata entonces, es de impulsar dispositivos culturales, pero también 
educativos que coloquen a los pescadores al tanto de estas necesidades productivas actuales y de sus propias posibilidades para mantenerse en el sector.

4.1. La pesca artesanal frente al tema de la calidad ambiental y la sostenibilidad

La sostenibilidad contiene implicaciones ambientales que se reflejan en la necesidad de la pesca artesanal de mantener una relación "amistosa" con la naturaleza, de manera que, el hecho de realizarse a pequeña escala, no significa que sea inocua para el deterioro de los ecosistemas en los que interviene. En Ecuador, algunos puertos pesqueros artesanales no cuentan con la infraestructura necesaria para impedir que los residuos de la actividad pesquera, en su proceso de almacenamiento y distribución, una vez capturado el pez, sean eliminados completamente esos desechos, lo que puede provocar un incremento de la contaminación ambiental y déficit de sus condiciones de sostenibilidad. Incrementar la contaminación ambiental juega en contra, no solo de la sostenibilidad de los ecosistemas pesqueros, sino de la calidad y cantidad de producto que se pueda obtener de ellos.

Estas son las circunstancias que influyen en las regulaciones que, en el marco de sus competencias, el gobierno ha impuesto a la pesquería artesanal, en cuanto al "...manejo de desechos, usos de los recursos e incluso la sustitución de esquemas o modelos de producción" (Oñate, 2015). La Constitución Nacional de 2008, establece una serie de parámetros regulatorios para preservar los derechos de contar con un ambiente sano, en equilibrio y sostenibilidad ecológica. En su artículo 14, el texto constitucional reconoce esos derechos y declara el interés público para la conservación del ambiente, el cuidado del equilibrio de los ecosistemas y la preservación de la biodiversidad; principios todos estos, de obligatorio cumplimiento para quienes se dedican al sector pesquero, incluyendo, por supuesto, el artesanal (Asamblea Nacional Constituyente, 2008).

El cumplimiento de los preceptos ambientales, son -además- una manera de mantener la coherencia de la pesca artesanal con sus técnicas y procedimientos, lo que coloca a estas normas, en sintonía con la cultura que hay detrás de la actividad pesquera. Siendo así, el entramado jurídico que resguarda el desarrollo ecológico de la pesca, incentiva igualmente sus vínculos con el enfoque de la sostenibilidad, algo que le da ventaja frente a sus pares ubicados en el sector 
industrial, donde la posibilidad de mantener el cumplimiento normativo, choca en muchos casos, con sus necesidades de expansión y cobertura de las demandas que hay sobre la importación del producto pesquero en el contexto internacional. A manera de síntesis en este apartado, la figura 4 presenta una ilustración de los elementos normativos que, en Ecuador, mantienen el marco regulador para la preservación de la calidad ambiental:

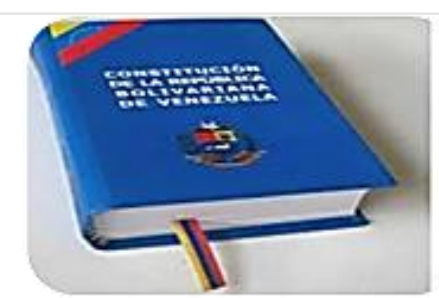

Artículos 10, 13, 14 y 66

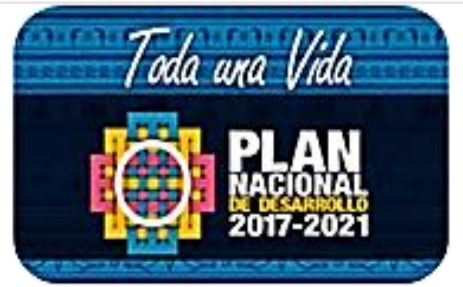

Obj. 6; Obj. 7; Obj. 11; Obj. 12

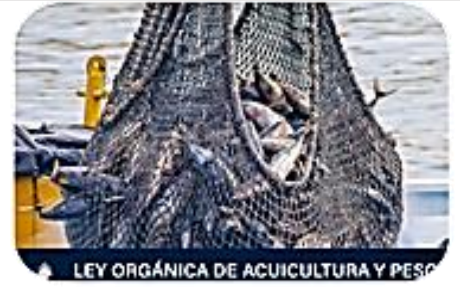

Artículos 1, 3, 5,19

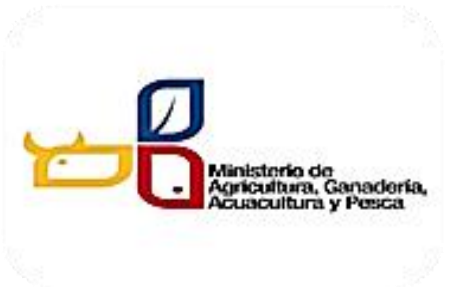

Artículo 4

Figura 4. Marco normativo en Ecuador, relativo a la sostenibilidad ambiental Fuente: Elaboración propia

4.2. Algunos cambios necesarios en la pesca artesanal de cara a su sostenibilidad y la globalización del mercado

La pesca artesanal en el Ecuador debe canalizar una serie de cambios en su operatividad, en la perspectiva de mantenerse en el sistema económico, con ciertos estándares de calidad y de sostenibilidad ambiental. Estos cambios incluyen, tanto el modo en que se asumen las relaciones con la naturaleza, como la cultura del trabajo, que debe articularse con la demanda internacional, muy relacionada con otras exigencias gastronómicas y productivas. Se entiende, de esta manera, que las necesidades de transformación son integrales, tanto en el contexto de la producción, 
como en el terreno de la socialización cultural. Además, siendo la pesca una actividad del sector primario, de carácter extractivo, la preservación de su esencia, pasa -como ya se dijo anteriormente- por una re-educación de los pescadores para mantener su sincronía con la realidad de la globalización (Quezada \& Álvarez, 2001).

El consumo que se abastece desde la pesca artesanal es tan importante como indiscutible. Solamente en el mercado interno de América Latina, ya para los inicios de este siglo, se estimaba que la mitad del producto llegaba desde ese tipo de pesca y, también, en el campo de la obtención de divisas, la producción artesanal del mercado pesquero empezó a ser importante en esa primera década, dada la globalización cada vez más extensa de la economía, lo que representa otro incentivo para que los pescadores involucrados con la actividad a pequeña escala, asumieran mayores retos, en cuanto a la utilización más eficiente de sus métodos de captura, sin que esto fuese a incrementar los efectos perniciosos sobre el ambiente natural.

El enfoque de la sostenibilidad ambiental en el contexto de la pesca artesanal y su relación con el mercado global, requiere además, mantener esquemas informativos que contribuyan para la construcción de una conciencia ecológica en los mismos consumidores, quienes deben presionar por la obtención de un producto, cuyo origen provenga de sistemas productivos respetuosos del medio ambiente, lo que nos habla de un modelo de relaciones de corresponsabilidad entre el Estado, los pescadores y los consumidores, todos con su cuota de compromiso. En el ámbito del consumo, tal como indica Pedroza (2020: 79), "la idea es controlar la demanda, para que a su vez las condiciones bajo las cuales esta se satisface se consigan de manera responsable y sustentable".

Desde el campo estrictamente productivo, las modificaciones éticas y axiológicas que se plantean desde la globalización para los contextos locales, existen necesidades que no pueden ser "medidas" en el sentido cuantitativo del término: el modo de vida de los pescadores artesanales de Ecuador se ha visto impactado en su simbología y representaciones sociales, al tener que adecuarse a las demandas de un proceso que descarta las prácticas autárquicas y promueve una homologación de técnicas en aras de favorecer la explotación intensiva y extensiva de la naturaleza, aun cuando haya preceptos normativos que cumplir. 
En suma, la realidad socioproductiva de quienes se dedican a la pesca artesanal en Ecuador, vive en un constante fluir de cambios que -independientemente de su ubicación y su contexto natural- que debe ser atendida para no fenecer en la vorágine de un proceso globalizador que no atiende a particularidades culturales. Ciertamente, se han dado importantes progresos en el ámbito institucional del país que, respondiendo en parte al paradigma del "buen vivir", como modelo de desarrollo, favorecen un rostro de sostenibilidad para la pesca artesanal y le provee de las herramientas necesarias para mantenerse como una opción de vida para ingentes poblaciones ecuatorianas que han permanecido ligadas a esta actividad desde épocas muy antiguas.

\section{Conclusiones}

Las prácticas socioproductivas que están involucradas en la pesca artesanal en Ecuador, definen en buena parte sus relaciones con el enfoque de la sostenibilidad ambiental. Ahora bien, cuando se realiza un esfuerzo analítico e interpretativo como este, para establecer los nexos entre la pesquería artesanal y la globalización, se producen algunos dilemas teóricos y prácticos que no son de fácil resolución. Es una realidad que, tanto en este país como en el resto de Latinoamérica, los pescadores artesanales, aunque mantienen sus métodos ecosistémicos, han necesitado adecuarse a los parámetros que impone la realidad del mercado mundial que, aunque favorece su expansión, en esa misma exigencia contradice la persistencia de algunos de esos métodos con perspectivas ambientalistas.

No obstante, la evolución del sector pesquero artesanal ha venido recibiendo el apoyo de políticas gubernamentales que han permitido el fortalecimiento de algunas áreas, como la implementación de políticas públicas para la consolidación portuaria orientada a la pesca artesanal, así como el impulso de cooperativas e iniciativas de participación popular que conectan de forma más directa las necesidades de la pesquería artesanal con los intereses estatales.

La investigación bibliográfica adelantada en el contexto de esta reflexión, también ha arrojado luces sobre la realidad de la pesca artesanal en su dimensión cultural, alertando acerca de la necesidad de impulsar mecanismos de resistencia respecto a los valores que impone la 
globalización en contra de una conciencia ambiental integral. No se trata únicamente de mantener la rentabilidad de la actividad pesquera a pequeña escala en Ecuador, es preciso igualmente- que se respeten los esquemas de racionalidad de las poblaciones costeras para preservar aquellos principios propios del ser ecuatoriano de esas zonas, con las implicaciones productivas que eso supone.

En definitiva, la pesca artesanal ya no es lo que antes fue, su diversificación va de la mano de su contextualización frente a un proceso de cambios que incluye los modos de vida. Sin embargo, es una prioridad mantener ese esquema institucional que posee formalmente el país o -más bien- potenciarlo, de manera que muchas de las exigencias contempladas en ese esquema, puedan acercarse más a la realidad actual del universo de relaciones que representa la pesquería artesanal en Ecuador.

\section{Referencias}

Asamblea Nacional Constituyente. (20 de octubre de 2008). Constitución Nacional de la República del Ecuador. Quito, Ecuador. Obtenido de https://www.oas.org/juridico/pdfs/mesicic4_ecu_const.pdf

Celaya, M., \& Almaraz, A. (2018). Recuento histórico de la normatividad pesquera en México: un largo proceso de auge y crisis. Entreciencias: Diálogos en la Sociedad del Conocimiento, 32-56. Obtenido de https://www.redalyc.org/jatsRepo/4576/457654930004/457654930004.pdf

Copelli, G. (2018). La globalización económica del siglo XXI. Entre la mundialización y la desglobalización. Estudios Internacionales, 57-80. Obtenido de https://revistas.uchile.cl/index.php/REI/article/download/52048/57285/179679

Herrera, M., Castro, R., Coello, D., Saa, I., \& Elías, E. (2014). Puertos, caletasy asentamientos pesqueros artesanales en la Costa Continental del Ecuador. Quito: Instituto Nacional de pesca. Obtenido de http://institutopesca.gob.ec/wp-content/uploads/2017/08/INP_BE_A4_Nl.pdf

Hernández, C. G.; Hurtado Hurtado, J. (2020). Escenarios prospectivos pospandemia para la internacionalización del sector agroalimentario de Ecuador al año 2035, Revista de Estudios Políticos y Estratégicos, 8-2: 36-66.

León, W., Núñez, L., Valencia, A., \& Cedeño, J. (2017). La Pesca Artesanal un legado del saber ancestral, provincia de Santa Elena. Revista de Investigaciones Sociales, 51-63. Obtenido de https://www.ecorfan.org/republicofnicaragua/researchjournal/investigacionessociales/journal/ vol3numl0/Revista_de_Investigaciones_Sociales_V3_N10_6.pdf 
López, G., \& Espeso, P. (2020). Pesca artesanal, patrimonio cultural y educación social. El pesacador murciano como transmisor cultural. Revista murciana de antropología, 11-32. doi:https://dx.doi.org/10.6018/rmu/427471

Méndez, M. (2020). Territorialidades en tensión: el caso de los pescadores artesanales en el Delta del Paraná (2012-2017). Huellas, 195-215. doi:http://dx.doi.org/10.19137/huellas-2020-2411

Ministerio de Acuacultura y Pesca . (15 de junio de 2020). Organiganización pesquera en el Ecuador. Obtenido de http://acuaculturaypesca.gob.ec/la-institucion/funcionarios

Oñate, H. (abril de 2015). Análisis de la gestión de residuos de las embarcaciones de pesca artesanal y su influencia en la calidad ambiental y turística de la playa en Puerto Cayo-Cantón Jipijapa Guayaquil, Ecuador. Obtenido de http://repositorio.ug.edu.ec/bitstream/redug/26464/1/T-UG-DP-MAA-027.pdf

Pazmiño , G., Gallardo , W., Ortiz, S., \& Beltrán, D. (2017). La implementación de políticas públicas como mecanismo para el desarrollo del talento humano y de los sectores pesqueros del Ecuador. Comercio y negocios, 84-107. Obtenido de https://revistasdigitales.upec.edu.ec/index.php/comercionegocio/article/download/441/469/147 7

Pazmiño, G. (2017). Situación actual del sector pesquero artesanal del Ecuador ante los cambios de la matriz productiva del país y mejora de los puertos pesqueros artesanales. Revista Perfiles gerenciales, 59-71. Obtenido de https://revistas.unilibre.edu.co/index.php/per_ger_humano/article/view/4528

Pedroza, c. (2020). Globalización, mercados y el futuro de las pesquerías. Ambiente y Desarrollo, 71-82. Obtenido de https://dialnet.unirioja.es/descarga/articulo/4927151.pdf

Quezada, P., \& Álvarez, B. (2001). Modo de producción y modo de vida de la pesca artesanal en una caleta pesquera rural: el proceso de transformación productiva y sus implicancias sobre la formación cultural de Isla Chaullín, Región de Los Lagos. Lider, 93-112. Obtenido de http://ceder.ulagos.cl/lider/images/numeros/8/8.

[LIDERVOL8]Mododeproduccionymodo20devidadelapescaartesanal.pdf

Salazar, S. (2013). Situación actual de la pesca artesanal en Costa Rica. Anuario de Estudios Centroamericanos,, 1-44. Obtenido de https://www.redalyc.org/pdf/152/15233381014.pdf

Solís, E., \& Díaz, G. (2018). Pescadores artesanales y uso del borde costero: caracterización socioespacial en la comuna de Puerto Montt. Periodo 1991-2013. Revista de estudios maritimos y sociales, $160-181$. Obtenido de http://estudiosmaritimossociales.org/rems/remsl2/Sol\%C3\%ADs_D\%C3\%ADaz.pdf. 
Soriano, J. (2019). La pesca artesanal en el marco de la soberanía alimentaria. Conferencia plurinacional e intercultural de soberanía alimentaria, (págs. 1-9). Quito. Obtenido de http://www.soberaniaalimentaria.gob.ec/2019/ForoInternacionaSA/Ponencias/Fomentolaprod uccion/Lapescaartesanalenelmarcodelasoberaniaalimentaria.pdf

Vázquez, A., \& Terazone, K. (2017). Desarrollo sostenible, "Buen Vivir" y la universidad ecuatoriana. RECUS, 27-32. Obtenido de https://dialnet.unirioja.es/descarga/articulo/6719876.pdf

Zurita, X. (23 de mayo de 2016). Metodología para el cambio de matriz de producción aplicado a los pescadores artesanales. Guayaquil, Ecuador. Obtenido de http://repositorio.ucsg.edu.ec/handle/3317/5980. 